\title{
Spatio-Temporal Patterns of Urban Forest Basal Area under China's Rapid Urban Expansion and Greening: Implications for Urban Green Infrastructure Management
}

\author{
Zhibin Ren, Xingyuan He, Haifeng Zheng and Hongxu Wei * (1) \\ Key Laboratory of Wetland Ecology and Environment, Northeast Institute of Geography and Agroecology, \\ Chinese Academy of Sciences, Changchun 130102, China; renzhibin1985@163.com (Z.R) \\ hexingyuan@iga.ac.cn (X.H.); zhenghaifeng@iga.ac.cn (H.Z.) \\ * Correspondence: weihongxu@iga.ac.cn; Tel.: +86-431-8253-6084; Fax: +86-431-8253-6084
}

Received: 13 April 2018; Accepted: 11 May 2018; Published: 17 May 2018

Abstract: Urban forest (UF) basal area is an important parameter of UF structures, which can influence the functions of the UF ecosystem. However, the spatio-temporal pattern of the basal area in a given UF in regions under rapid urbanization and greening is still not well documented. Our study explores the potential of estimating spatio-temporal UF basal area by using Thematic Mapper (TM) imagery. In our study, the predicting model was established to produce spatiotemporal maps of the urban forest basal area index in Changchun, China for the years 1984,1995, 2005, and 2014. Our results showed that urban forests became more and more fragmented due to rapid urbanization from 1984 to 1995. Along with rapid urban greening after 1995, urban forest patches became larger and larger, creating a more homogeneous landscape. Urban forestand its basal area in the whole study area increased gradually from 1984 to 2014, especially in the outer belts of the city with urban sprawl. UF basal area was $27.3 \times 10^{3} \mathrm{~m}^{2}, 41.3 \times 10^{3} \mathrm{~m}^{2}, 45.8 \times 10^{3} \mathrm{~m}^{2}$, and $65.1 \times 10^{3} \mathrm{~m}^{2}$ of the entire study area for the year 1984, 1995, 2005, and 2014, respectively. The class distribution of the UF basal area index was skewed toward low values across all four years. In contrast, the frequency of a higher UF basal area index increased gradually from 1984 to 2014. Besides, the UF basal area index showed a decreasing trend along the gradient from suburban areas to urban center areas. Our results demonstrate the capability of TM remote sensing for understanding spatio-temporal changing patterns of UF basal area under China's rapid urban expansion and greening.

Keywords: urban forest; urbanization; sampling plots; Landsat TM; basal area

\section{Introduction}

During the last three decades, many serious urban environmental problems have evoked considerable social concerns in China [1]. Many cities in China have set up a lot of environmental improvement strategies such as a focus on urban forest (UF) establishment [2]. UFs in cities are the most important parts of urban ecosystems [3]. The establishment of UFs can be considered as an important way to improve the urban environment [3]. Urban forests could provide many ecological functions to resolve urban environmental problems [4,5], such as reducing urban air pollutant concentrations $[6,7]$, sequestering atmospheric $\mathrm{CO}_{2}[8,9]$, reducing storm water runoff $[10,11]$, mitigating the urban heat island [12,13], and providing a habitat for organisms [14,15].

UF basal area is considered as an important component of UF structures, which can influence UF ecosystem functions [16,17]. In the past six decades, China has experienced rapid urbanization and urban greening [18]. The urban population in China is predicted to reach 1.5 billion with an 
urbanization level of $50 \%$ by the end of 2020 [19]. With the continuous development of urbanization, UF has great development potential in China [20]. The Chinese government have placed an increasing emphasis on UF development in recent decades [21,22]. UF City Programs were proposed by the Chinese government from 2004. Many governmental regulations relating to urban greening have been introduced. Urban forests in China could experience a dramatic change due to intensive human activities, such as urbanization and urban greening. However, the comprehensive effects of urbanization and greening on the spatio-temporal patterns of UF basal area have still not been understood. Therefore, the accurate and timely estimation of spatiotemporal UF basal area is necessary and useful for urban managers to understand UF functions and maximize the environmental benefits of UFs under China's rapid urban expansion and greening. To the best of our our knowledge, the spatiotemporal dynamic patterns of the UF basal area under China's rapid urbanization and greening have rarely been studied and are not yet fully understood.

As we know, the acquisition of spatial-temporal UF basal area often depends on conventional intensive and costly plot-based field work [23-25]. In addition, it is very tough to obtain spatial-temporal patterns of UF basal area at the urban landscape scale through direct field sampling measurements. The lack of a consistent area-wide UF basal area would impact our ability to conduct the ecological analyses of UF functions at a landscape level. Using remote sensing techniques, the estimation of UF basal area should be connected with various vegetation indices developed from remote sensing data to overcome these limitations [26]. Among these remote sensing data, the higher resolution remote sensing dates such as QiuckBird remote sensing and Systeme Probatoire d'Observation dela Tarre (SPOT) or eye-level photography can be used for extracting urban forest structures with a high accuracy. However, these data are often more expensive. While Landsat Thematic Mapper (TM or Enhanced Thematic Mapper (ETM+)) imagery has a poorer resolution and issues with mixed pixels, it is easily accessed, less expensive, and widely used all over the world to estimate forest structural attributes. Many researchers have demonstrated that some indices obtained from TM or ETM ${ }^{+}$imagery data such as the Normalized Difference Vegetation Index (NDVI), simple ratio (SR), and green normalized difference vegetation (GNDVI), are significantly correlated with forest structural attributes measured on the ground such as canopy cover, stem density, diameter at breast height, tree height, base area, leaf area index, biomass, etc. [26-30]. The most commonly used spectral indicator extracted from TM or $\mathrm{ETM}^{+}$imagery is the Normalized Difference Vegetation Index (NDVI). Some researchers have showed that the NDVI has a significant relationship with ground measured natural forest structures [28,29]. Previous studies have achieved some degrees of success in estimating the forest basal area index from TM or ETMY data in natural areas worldwide. However, the conclusions about relationships between forest basal area and NDVI vary, depending on the characteristics of the study areas [30]. UFs are usually very different from natural forests, which are heterogeneous, fragmented and scattered, and surrounded by many impervious surfaces $[16,17]$. Therefore, the relationships found between vegetation indices and natural forest structures may be different from the relationships between vegetation indices and urban forest structural attributes. Whether NDVI extracted from TM or $\mathrm{ETM}^{+}$ imagery can stilf be used for estimating UF basal area is still unknown. Based on our literature review [23-29], there have been few studies on estimating spatiotemporal patterns of UF basal area with $\mathrm{TM}_{\text {or }} \mathrm{ETM}^{+}$imagery.

Based on field measurements and TM remote sensing data acquired in four different years (1984, 1995, 2005, and 2014) from the City of Changchun, China, our study aims to characterize the changing patterns of UF basal area from Landsat TM imagery from 1984 to 2014 under two key forces: the fast urbanization process and the urban greening policies. The purposes of our research are to: (1) examine the usefulness of TM remote sensing at different times in estimating spatio-temporal changes of UF basal area; (2) develop a model for predicting UF basal area by coupling field measurements with TM remote sensing; (3) explore the dynamic spatio-temporal patterns of UF basal area in the City of Changchun, China from 1984 to 2014; and (4) study the implications of UF establishments for urban environmental improvement under China's rapid urban expansion and greening. 


\section{Methods}

\subsection{Study Area}

Our study was conducted within the fifth-ring road of Changchun $\left(125^{\circ} 09^{\prime}-125^{\circ} 48^{\prime}\right.$ E, $43^{\circ} 46^{\prime}-43^{\circ} 58^{\prime} \mathrm{N}$ ) (Figure 1), which is the capital of Jilin Province and an important social-economic center of northeastern China. Changchun is located in the hinterland of the Northeast Plain and had a total population of 3.6 million by the end of 2010. The average total yearly precipitation in Changchun is $567 \mathrm{~mm}$ and the average temperatures of the cold winter and hot summer are $-14{ }^{\circ} \mathrm{C}$ and $24{ }^{\circ} \mathrm{C}$, respectively. Changchun is called the "Forest city", with an average forest cover rate of $45 \%$. Urban forest species are the most abundant with 43 families, 86 genera, and 211 species [24]. Since 1980, Changchun has experienced an accelerated progress of urbanization in temperate regions of Northern China [31], which might have caused dramatic changes of UF structure and species composition. Therefore, Changchun is an ideal city for analyzing the spatiotemporal patterns of UF basal area under China's rapid urban expansion and greening.

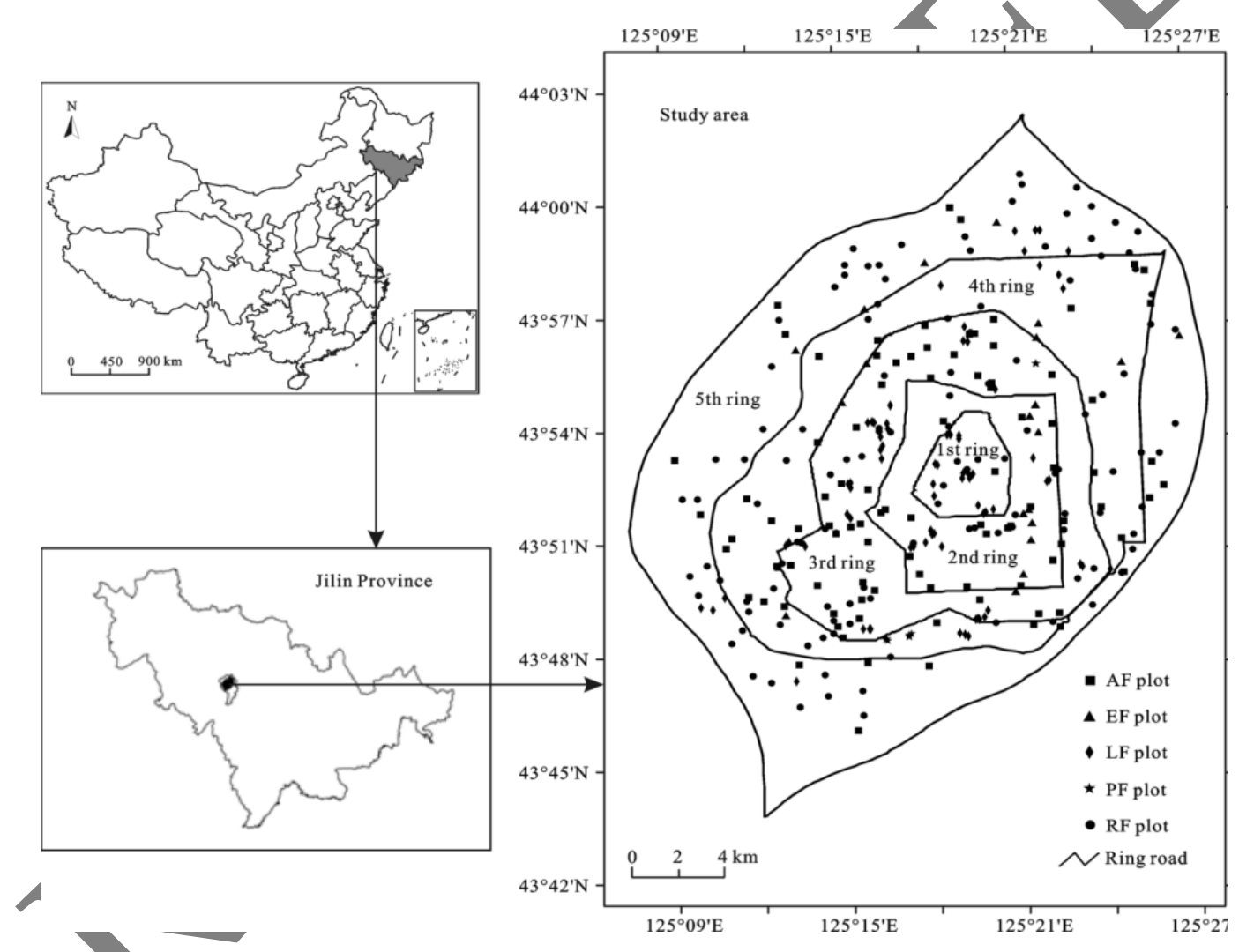

Figure 1. The study area located within the fifth-loop road in the City of Changchun, China. AF: attached forest; EF: ecological and public welfare forest; LF: landscape and relaxation forest; PF: production and management forest; RF: road forest.

\subsection{Image Data and Processing}

The four scenes of TM images with a resolution of $30 \mathrm{~m}$ were collected on 14 September 1984, 29 September 1995, 8 September 2005, and 3 October 2014 with a cloud cover less than 5\% of scenes. These four Landsat scenes across three decades were within the same phenological stage. In Changchun, the trees began shedding their leaves in early November and the leaves were still on the trees on 3 October. Therefore, the four scenes of TM images can be used in our study for urban forest research. The atmospheric correction for the TM images was first undertaken and then the TM raw digital numbers (DN) were converted into surface radiance values by following the procedures 
provided by Chander and Markham [32]. Finally, the TM images were geo-referenced to the Universal Transverse Mercator (UTM) coordinate system with a root mean square error (RMSE) of less than 0.5 pixel by using 33 ground control points taken from topographic maps. Based on four scenes of TM images, the Normalized Difference Vegetation Index (NDVI) index was further calculated in ENVI 4.6 through the equation of NDVI $=(\mathrm{b} 4-\mathrm{b} 3) /(\mathrm{b} 4+\mathrm{b} 3)$, where $\mathrm{b} 3$ and $\mathrm{b} 4$ are the surface reflectance values in TM bands 3 and 4, respectively. To conduct a spatiotemporal analysis of UF basal area with multitemporal TM images, it is necessary to normalize NDVI maps calculated from the multitemporal TM images to eliminate environmentally introduced radiometric effects. The relative radiometric correction method of pseudo-invariant features (PIF) was applied in our study $[33,34]$. This procedure uses one image as a reference image (2014) and adjusts the radiometric properties of all other images $(1984,1995$, and 2005) to it by the analysis of invariant features, such as roads, rooftops, and deep water. In our study, seventy-five spatial evenly distributed regions of interest for invariant features (including 25 from roads, 30 from rooftops, and 20 from water bodies) located on the mul-titemporal images were manually selected. The average NDVI in each interest region was then used to develop a linear normalization model between the reference image (2014) and the subject (i.e., uncorrected) images (1984, 1995, and 2005). The normalized subject images (Figure 2) were obtained using the following equation:

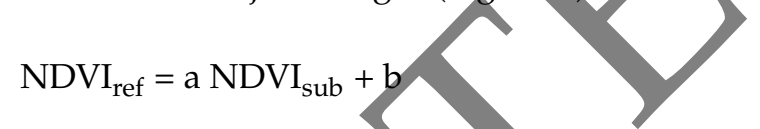

where $\mathrm{NDVI}_{\text {ref }}$ is the reference image (i.e., 2014 image); and NDVI sub is the subject image (i.e., 1984, 1995, and 2005 images). The scene normalization coefficients of NDVI before and after normalization are listed in Table 1.

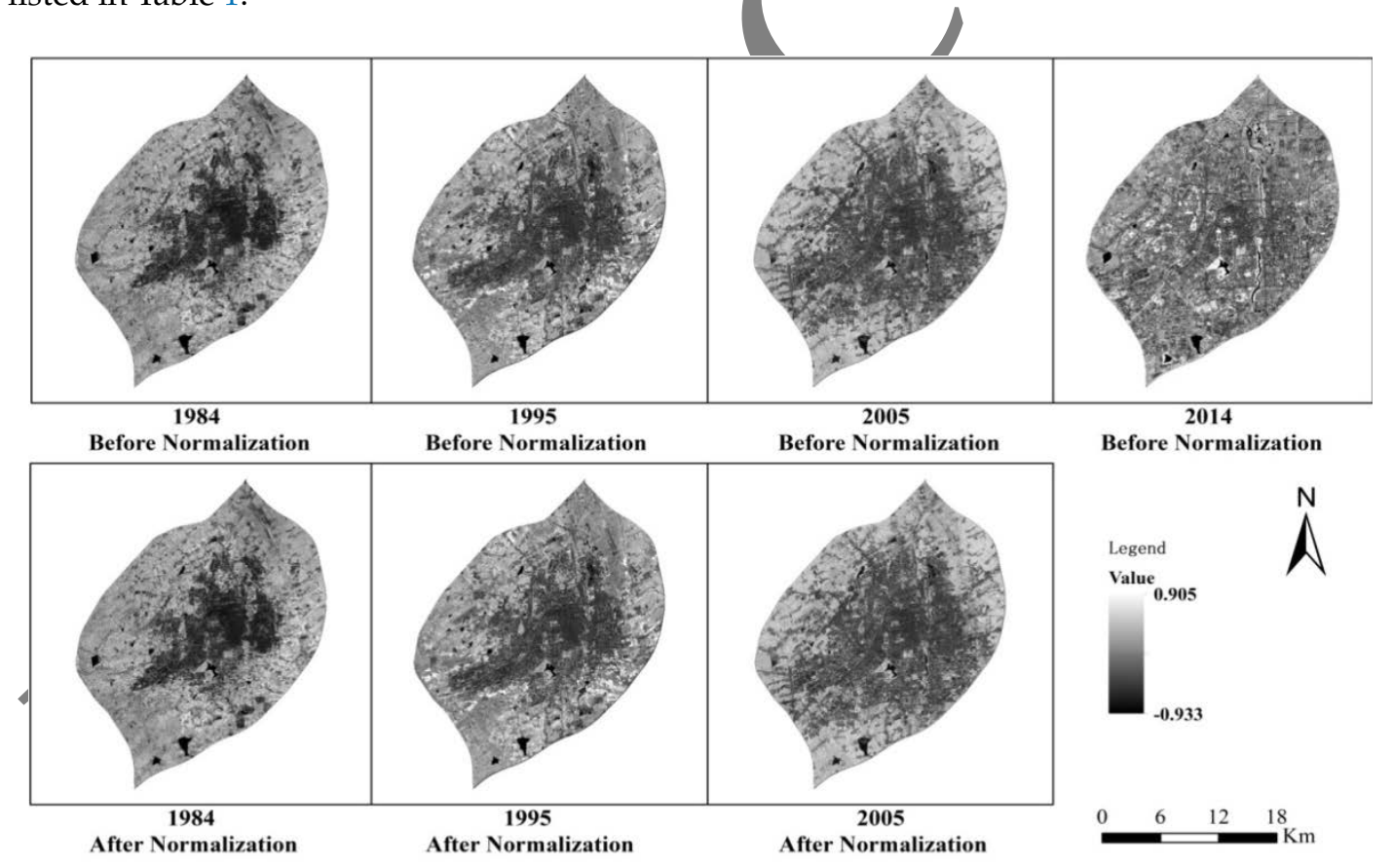

Figure 2. The NDVI images before and after normalization.

Table 1. The image normalization coefficients and the correction coefficients for each subject image.

\begin{tabular}{cccc}
\hline & $\mathbf{1 9 8 4}$ & $\mathbf{1 9 9 5}$ & $\mathbf{2 0 0 5}$ \\
\hline $\mathrm{a}$ & $0.712^{* *}$ & $0.745^{* *}$ & $0.876^{* *}$ \\
$\mathrm{~b}$ & $-0.154^{* *}$ & $-0.103^{* *}$ & $-0.095^{* *}$ \\
$R^{2}$ & 0.725 & 0.712 & 0.842 \\
$p^{*}$-value & 0.00 & 0.00 & 0.00 \\
\hline \multicolumn{2}{c}{ ** Significant at the 0.01 probability level. }
\end{tabular}




\subsection{Sampling Design and UF Basal Area Calculation}

Plot measurements: 159 random plots (sampling plots) throughout the study area were established in this study by using the methods from the Urban Forest Effects (UFORE) Model [35]. Field measurements of UFs were conducted during July and August 2013 and 2014 (Figure 3). The sampling plots were randomly selected to ensure that they were representative of the major types of urban landcover such as residential areas, road areas, park areas, and commercial areas in Changchun. Besides, sampling plots were required to be located in relatively homogenous patches greater than $1600 \mathrm{~m}^{2}$, and in this study, each of the 159 sampling plots was defined as a $30 \mathrm{~m} \times 30 \mathrm{~m}(0.09 \mathrm{ha})$ area to represent a TM pixel size. The coordinates of each sampling plot were recorded with a global positioning system (MG838GPS, UniStrong Company, Beijing, China) with the high-accuracy better than $1 \mathrm{~m}$, which were used to extract the NDVI value from multi-temporal TM derived NDVI maps. A total of 5693 tree individuals were measured from the 159 sampling plots. At each sampling plot, some UF structural attributes including tree species, vegetation types, stem density, diameter at breast height (DBH), tree height $(\mathrm{H})$, and crown size, were measured or collected. Finally, UF basal area $\left(\mathrm{m}^{2}\right)$ was considered as the cross-sectional area of all trees in a sampling plot and calculated at each plot in this study. The basal area index (in $\mathrm{m}^{2} / \mathrm{ha}$ ) is defined as the ratio of the cross-sectional area of all trees in a sampling plot to the plot ground area, as shown in Equation (1).

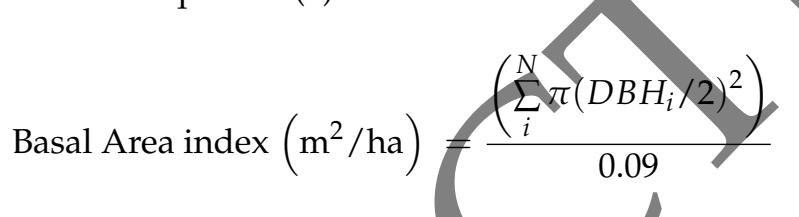

where $N$ is the number of trees in a sampling plot for the equation

After the calculation of UF basal area, NDVI values were extracted from the normalized TM images in ArcGIS 9.3 software (Environmental Systems Research Institute, Redlands, CA, USA) with the latitude and longitude of each sampling plot for later statistical analyses.

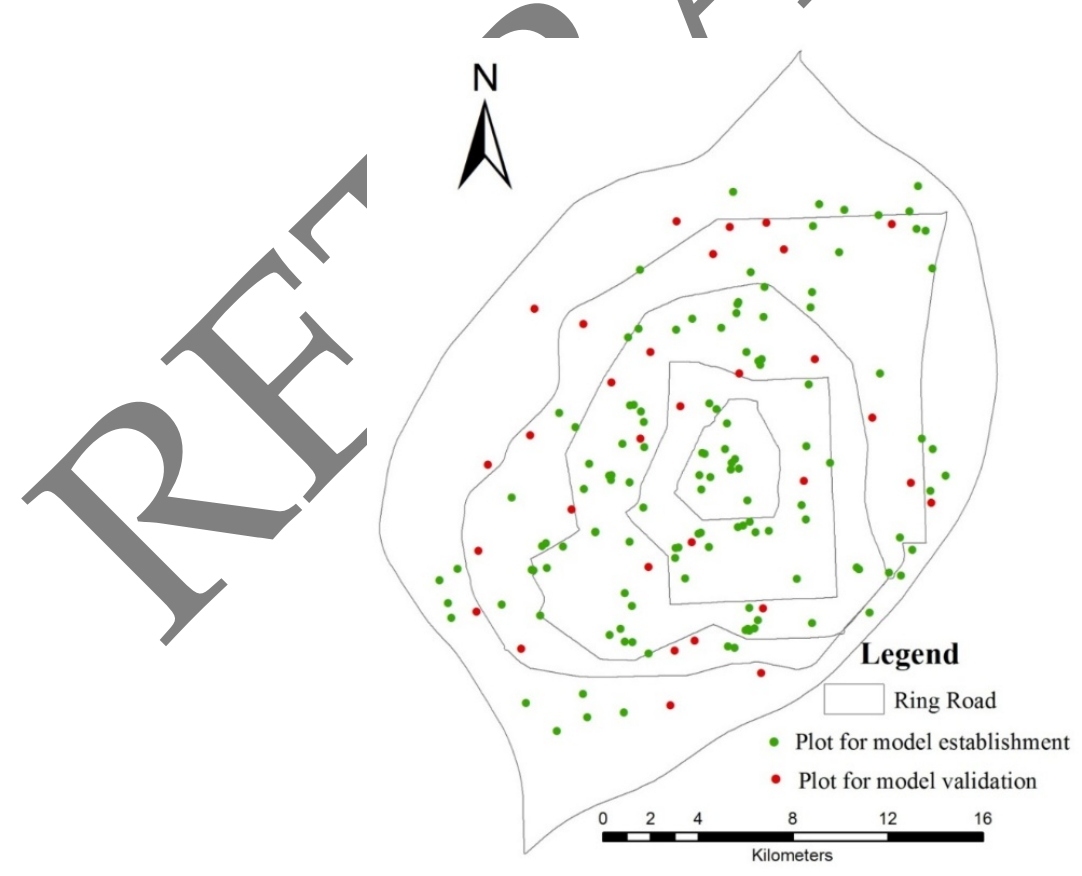

Figure 3. Map of 159 sampling plots in the City of Changchun.

\subsection{Spatio-Temporal Patterns of UF and Its Basal Area with TM Images}

UF can be defined as a synthesis between an organism and abiotic environment, which should reach a big enough area ( $>0.5 \mathrm{ha}$ ) and coverage with trees as the main body, considerably influence the 
surrounding environment, and provide ecological values and human landscape values [36]. In our study, it should be noted that only patches of urban vegetation with an area larger than 0.5 ha were extracted as UF. Based on four scenes of TM images, an object-based approach was used for UF extraction [37]. This approach did not classify single pixels, but groups of pixels that represent already existing objects in ArcGIS software (Environmental Systems Research Institute, Redlands, CA, USA), which is based on a supervised maximum likelihood classification. The TM images were firstly segmented into objects by an object-based approach and then assigned to a UFs class. An object-based approach is superior to traditional pixel-based classification [38]. For example, the salt-and-pepper noise is a form of noise sometimes seen on images, which can be caused by sharp and sudden disturbances from the image signal. It presents itself as sparsely occurring white and black pixels. The "salt-and-pepper" effect frequently found in pixel-based classification can be largely avoided when using an object-based approach for land cover classification. The historical high spatial resolution images in Google Earth were used as reference data for the accuracy assessment. An accuracy estimate was conducted based on 200 checkpoints for every respective year with historical high spatial resolution images in Google Earth as references for 1984, 1995, 2005, and 2014. The overall accuracies of UF extraction for $1984,1995,2005$, and 2014 were $89.24 \%, 90.43 \%, 91.58 \%$, and $93.12 \%$, respectively.

In order to produce the spatiotemporal maps of UF basal area index from historical TM imagery, NDVI was used to build the prediction model for UF basal area index. The corresponding regression model between UF basal area index collected from the 129 plots and NDVI extracted from the 2014 TM image was established to uncover quantitative relationships between them. In the analyses, the plot-based NDVI was used as the independent variable, while UF basal area index was used as a dependent variable. In this study, coefficient of determination $\left(R^{2}\right)$ for regression analysis between NDVI and UF basal area index was calculated to assess the relationship. To evaluate the reliability and accuracy of the established models, plot-based measured UF basal area index data at 30 plots (Figure 3) were used for validation. The variability is represented by the standard error. $R^{2}$ and RMSE were used to test the fitness of the predicting model at plots. A well-calibrated model should have a root mean square error (RMSE) that is small relative to the total observed variation and an $R^{2}$ close to one. All statistical analyses were carried out with standard statistical software, SPSS (Version 19.0, IBM Company., Chicago, IL, USA

Mapping UF basal area index: a vector, layer data of UF was first used to extract the NDVI of UF from 1984, 1995, 2005, and 2014 TM images in our study, and then the map of UF basal area index in 2014 was created by calculating pixel-based values of UF basal area index using the regression model developed with NDVI extracted from the 2014 NDVI image at the 129 plots and 2013-2014 field survey data. We also created spatio-temporal maps of UF basal area index from normalized NDVI images calculated from 1984, 1995, and 2005 TM images using the regression model of UF basal area index, developed with the 2014 NDVI image.

\section{Results}

\subsection{Urbanization in Changchun from 1980 to 2014}

Some variables of urbanization in Changchun were collected from the Statistics Yearbook of Cities in China (National Bureau of Statistics of China, 1980-2014). These variables include urban population, built-up area, and gross domestic product (GDP) per capita, which were used to assess the urbanization level in our study. The results showed that Changchun has experienced rapid urbanization during the last 30 years (1984-2014) (Figure 4). Compared to $89 \mathrm{~km}^{2}$ in 1984, urban build-up area reached $430 \mathrm{~km}^{2}$ in 2014, with a rapid increment during last three decades. Urban population increased from $110 \times 10^{4}$ in 1984 to $410 \times 10^{4}$ in 2014 , with an increment of $9 \times 10^{4}$ for each year. Meanwhile, GDP area per Capita also showed a rapid increase from 1984 to 2014. 


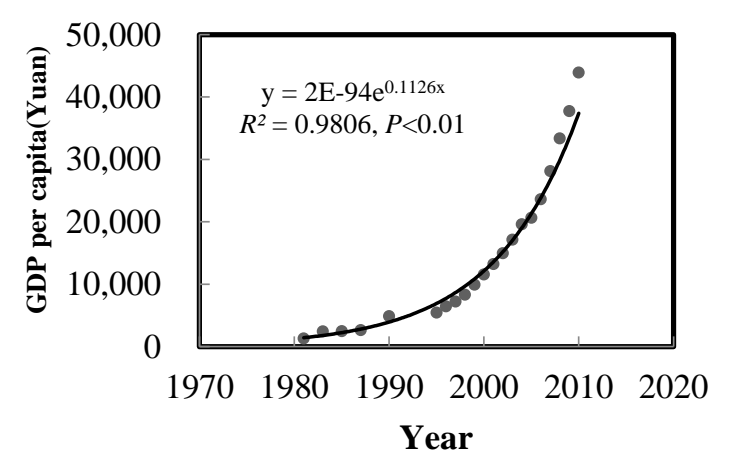

(a)
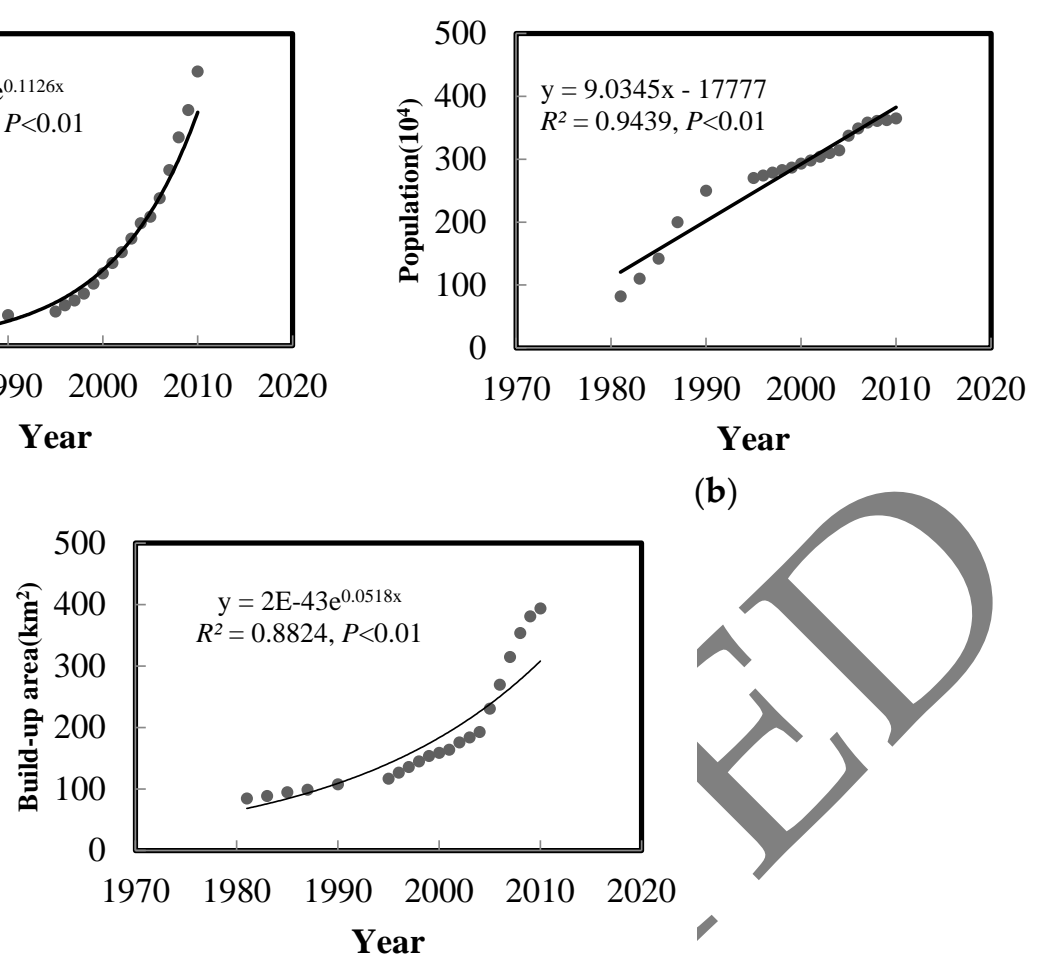

(b)

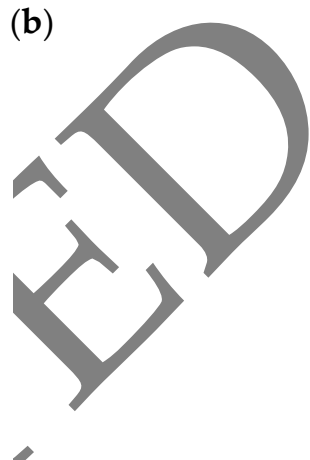

(c)

Figure 4. Urbanization process in Changchun city from 1980 to 2014. (a) GDP; (b) Population; (c) Build-up area.

\subsection{Spatial Assessment Model for UF Basal Area Index}

In order to produce the spatio-temporal maps of UF basal area index from historical TM imagery, NDVI was used to build the prediction model for UF basal area index. The results showed that the UF basal area index had a positive non-linear relationship with NDVI (Figure 5), which suggested that the UF basal area index increases non-linearly with the increase of NDVI. As seen in Figure 5, when NDVI was lower than 0.5 , the UF basal area index increased slowly with the increase of NDVI. However, when NDVI was larger than 0.5, the UF basal area index increased sharply (Figure 5). The non-linear model with NDVI as the independent variable could explain $69.2 \%$ of total variance of UF basal area index. Finally, the established regression model was then applied to produce the maps of UF basal area index from normalized historical NDVI images in 1984, 1995, 2005, and 2014, respectively. To evaluate the reliability and accuracy of the predicted model, 30 plot-based measured UF basal area index data were used for validation. A well-calibrated model should have a root mean square error (RMSE) that is small relative to the total observed variation and an $R^{2}$ close to one. Our results showed that the modeled UF basal area index compared closely with the plot-measured UF basal area index $\left(\right.$ RMSE $=1.3 \mathrm{~m}^{2} /$ ha; $\left.R^{2}=0.90\right)$ (Figure 6$)$. Ninety percent of the variance of UF basal area index among the 30 plots can be captured by the model. However, high UF basal area index values were slightly underestimated. Therefore, the established model is accurate and can be used to predict the UF basal area index. 


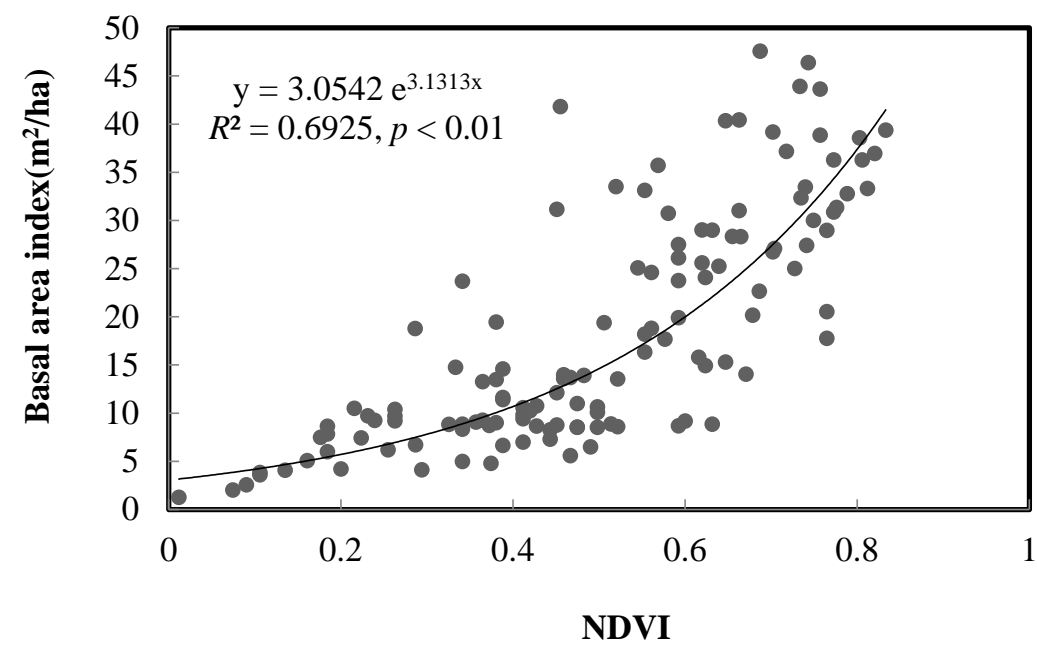

Figure 5. Regression analyses of NDVI with UF basal area index $(n=129, p<0.01)$

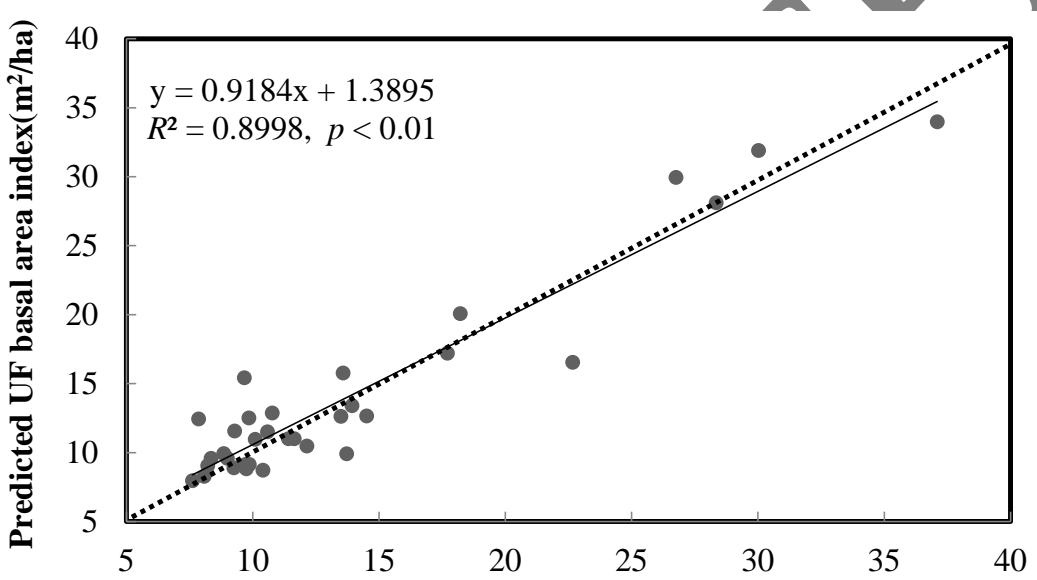

Measured UF basal area index(m²/ha)

Figure 6. Comparisons between plott-based measured UF basal area index and the modeled UF basal area index at the 30 sites $(n=30)$.

\subsection{Spatio-Temporal Distribution of UF and Its Basal Area}

The spatio-temporal patterns of UF over the past three decades (1984-2014) have changed dramatically (Figure 7), mirroring the intense urbanization and rapid development of urban greening in China. It is obvious that UF gradually expanded from downtown to the suburban area during the study period. UF coverage steadily increased from 15\% in 1984 to $25 \%$ in 2014 (Table 2). The UF area in 2014 increased by $63.1 \%\left(52.4 \mathrm{~km}^{2}\right)$ compared to 1984 . Our results revealed the clear changes of UF spatial configuration. The total number of UF patches in the Municipality area approximately increased by $99 \%$ from 1984 to 1995, and then decreased by 2.6\% from 1995 to 2005 and $27.8 \%$ from 1995 to 2014 (Table 2). Correspondingly, the values of mean UF patch size showed a decline of $43.4 \%$ from 1984 to 1995, but exhibited an increase of $14.9 \%$ from 1995 to 2005, and the increase was doubled from 2005 to 2014. These changes in landscape configuration suggest that the UF became increasingly fragmented due to intense urbanization from 1984 to 1995. Along with rapid urban greening after 1995 (Figures 7 and 8, Table 2), the UF patches became larger and larger, creating a more homogeneous landscape when compared with the spatial patterns in 1995. UF was mostly located in the urban central area in 1984 (Figures 7 and 8) and then distributed more evenly across the whole urban area in 
more recent years (2005 and 2014). In the study years of 1984, 1995, and 2005 (Figures 7 and 8), the UF coverage was higher in the two-ring area than that in the other-ring area. In 2014, the highest value of UF coverage occurred in the three/four-ring area. Spatial heterogeneity of UF change also existed from 1984 to 2014 . Our results showed that UF coverage in the suburban area (four to five-ring area) increased gradually from 1984 to 2014, but decreased sharply in the urban central area (one/ two-ring area) of the city (Figures 7 and 8). UF Patch numbers showed a decreasing trend from suburban areas to downtown for all the study years (Figures 7 and 8). From 1984 to 2014, UF patch numbers increased in all ring areas, especially in the five-ring area. Mean patch area of UF showed an increasing trend from suburban areas to the downtown area for the years 1995, 2005, and 2014 (Figures 7 and 8). Mean patch area of UF in the suburban area (five-ring) increased gradually from 1984 to 2014, but decreased sharply in the downtown area (one/two-ring area) of the city.

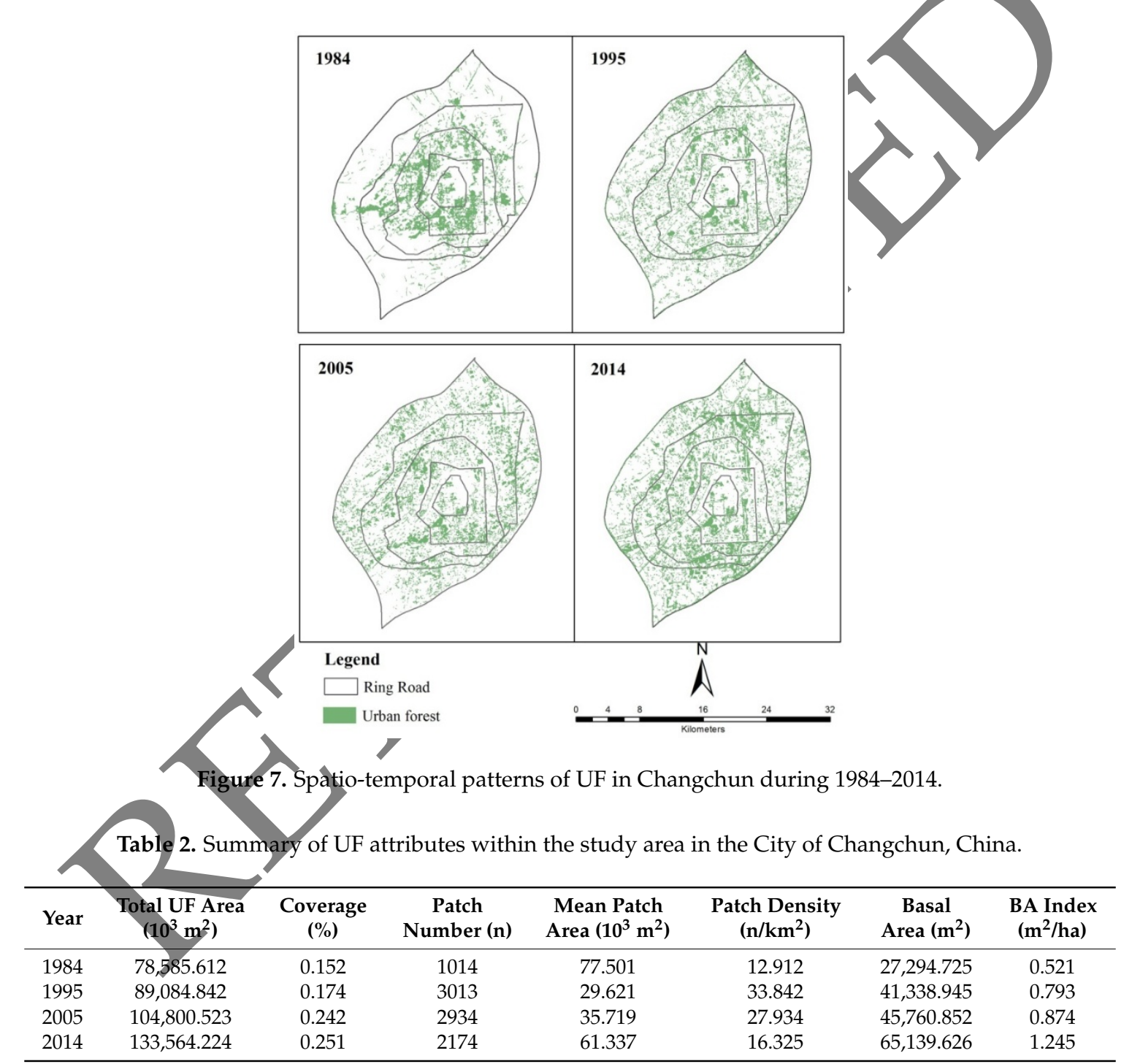

Note: UF basal area $\left(\mathrm{m}^{2}\right)$ was considered as the cross-sectional area of all trees in this study area. Basal area index $\left(\mathrm{m}^{2} / \mathrm{ha}\right)=$ Total basal area $/$ study area. 

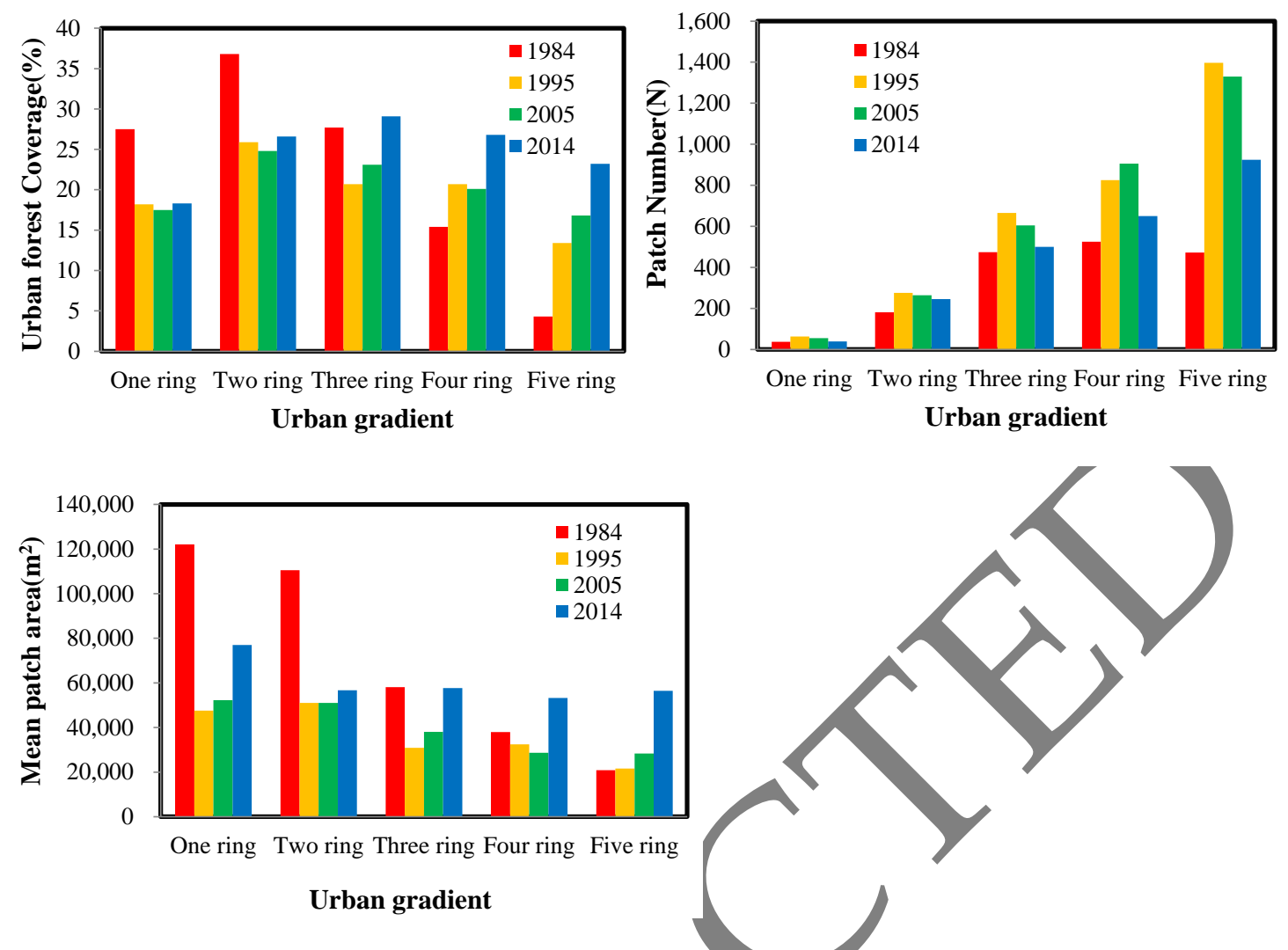

Figure 8. Urban forest coverage, patch characteristics, and basal area across ring road-based urban gradient.

By analyzing the pixel-based maps of UF basal area index in a GIS format, we found that they were highly dynamic among the years 1984, 1995, 2005, and 2014 (Figures 9 and 10). UF basal area was $27.3 \times 10^{3} \mathrm{~m}^{2}, 41.3 \times 10^{3} \mathrm{~m}^{2}, 45.8 \times 10^{3} \mathrm{~m}^{2}$, and $65.1 \times 10^{3} \mathrm{~m}^{2}$ of the entire study area in 1984 , 1995, 2005, and 2014, respectively. UF basal area in Changchun increased gradually from 1984, 1995, and 2005 to 2014, mirroring the intense urbanization and rapid development of urban greening in the city. In addition, the high spatial heterogeneity of the basal area was observed across the city. In 1984, pixels with values of UF basal area were mostly concentrated in downtown areas (Figures 9 and 10) and then distributed more evenly across the whole urban area in more recent years (2005 and 2014). UF basal area showed a decreasing trend from suburban areas to downtown areas in the years 1995, 2005, and 2014 (Figure 10). Meanwhile, the UF basal area index was higher in the two-ring area than that in the other-ring area in the city of Changchun for the years 1984, 1995, 2005, and 2014 (Figure 10). Our results also show that the different spatial changes of UF basal area have occurred across different urban gradients from 1984 to 2014. The UF basal area increased more in the suburban area than that in the downtown area (Figure 10). However, the UF basal area index exhibited a greater increase in the downtown area than that in the suburban area. 

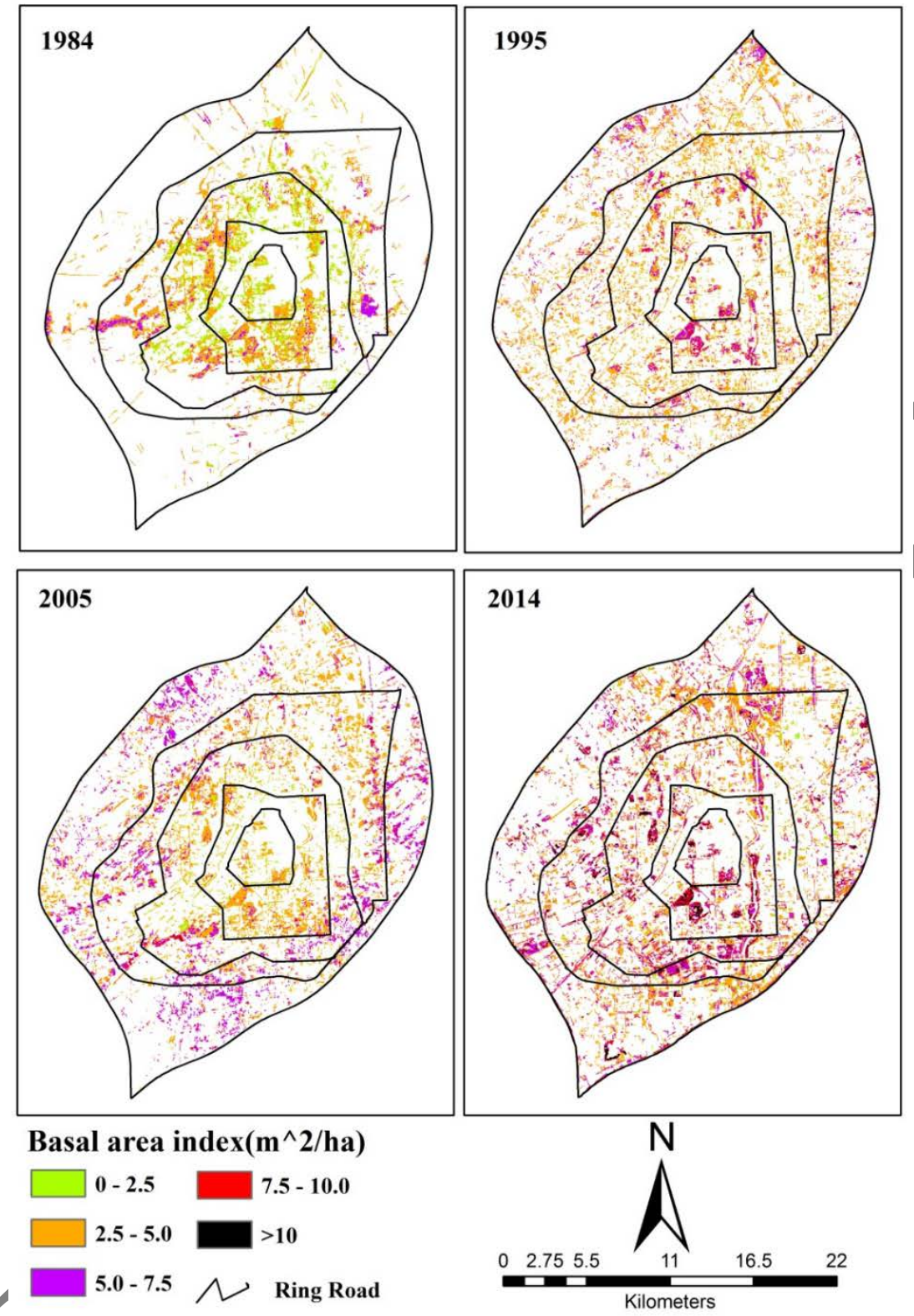

Figure 9. Spatiotemporal distribution of UF basal area index in the City of Changchun.

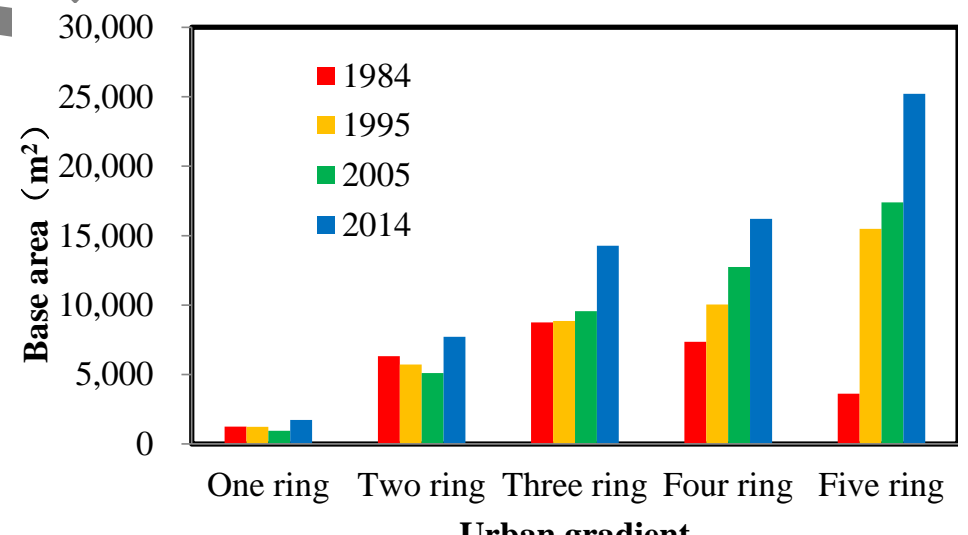
Urban gradient

Figure 10. Cont. 


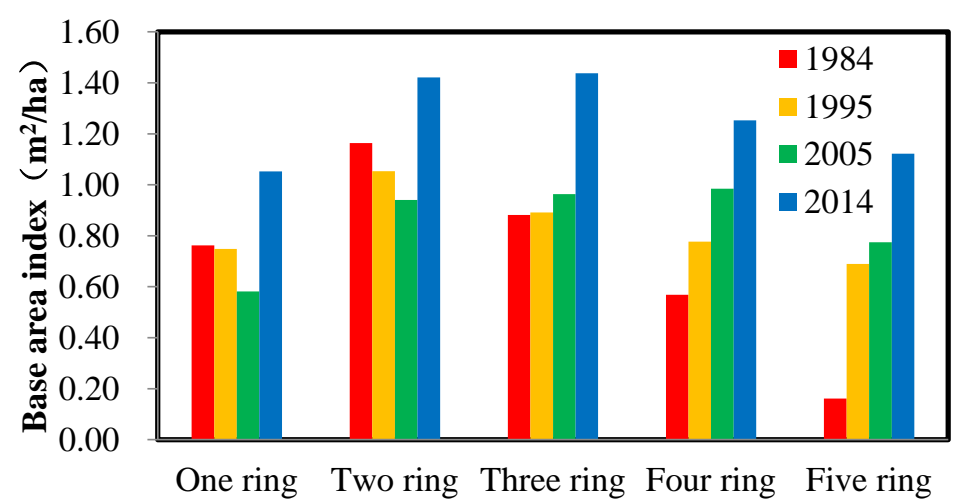

Urban gradient

Figure 10. UF basal area across urban gradient: UF basal area $\left(\mathrm{m}^{2}\right)=$ the cross-sectional area of all trees in the study area. Basal area index $\left(\mathrm{m}^{2} / \mathrm{ha}\right)=$ Total basal area/study area.

The class distributions of UF basal area index were all skewed toward low values in 1984, 1995, 2005, and 2014. The results showed that the UF basal area index in 1984, 1995, 2005, and 2014 with the highest frequency was $2.5-5 \mathrm{~m}^{2} /$ ha (Figure 11). The frequency of UF basal area index from $2.5-5 \mathrm{~m}^{2} / \mathrm{ha}$ was $59 \%, 71 \%, 56 \%$, and $45 \%$ in $1984,1995,2005$, and 2014 , respectively. However, the frequency of a lower UF basal area index (2.5-5 $\mathrm{m}^{2} / \mathrm{ha}$ ) decreased gradually from 1984, 1995, and 2005 to 2014. Meanwhile, the frequency of a higher UF basal area index ( $>5 \mathrm{~m}^{2} / \mathrm{ha}$ ) increased gradually from $14 \%$ in 1997 to $48 \%$ in 2014. About $14 \%$ of UF basal area index values were above $7.5 \mathrm{~m}^{2} /$ ha in 2014 , but there were just a few of pixels with a UF basal area index $>7.5 \mathrm{~m}^{2} /$ ha in 1984, 1995, and 2005.

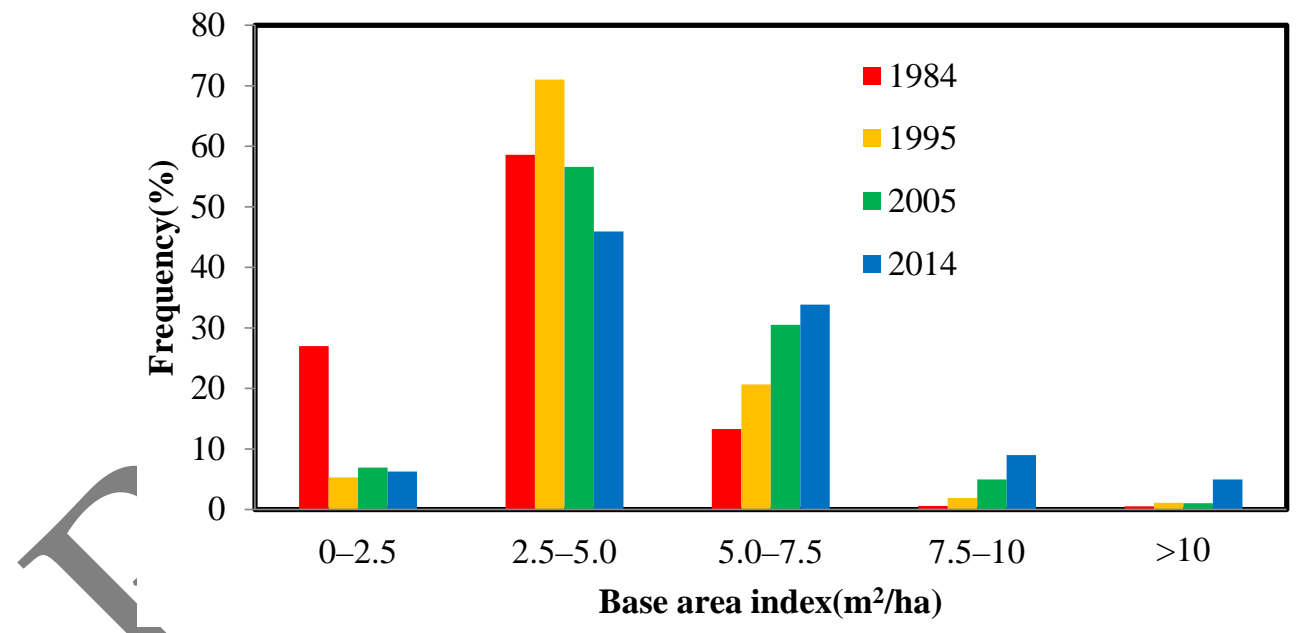

Figure 11. Histograms of the frequency statistics for UF basal area index, calculated from pixels with UF in the study area of Changchun, China.

\section{Discussion}

\subsection{The Spatio-Temporal Estimation of UF Basal Area Index}

Our results demonstrated the potential of using mul-titemporal TM imagery to characterize spatiotemporal changing patterns of UF basal area in practice. UF basal area could be still estimated by NDVI extracted from TM imagery just like natural forest basal area that could be predicted well by NDVI $[27,30]$. However, the relationship between forest basal area and NDVI was weaker in the urban area than that in the natural area $[8,28]$. One possible reason for this might be that the environment of UFs is very different from that of natural forests. Usually, urban heterogeneous and fragmented 
environments may result in a mixed pixel problem. Therefore, the mixed pixel issue might be the main reason for the confusion of estimating UF basal area by NDVI. The approach of establishing a model to predict UF basal area has been successful, but has serious limitations. The major limitations of using vegetation indices (VIs) to estimate forest basal area are that VIs frequently lose sensitivity and saturate at a moderately high above-ground biomass (AGB) or leaf area index (LAI). Many studies [39-41] have reported that models between VIs and basal area or biomass are curvilinear and there is a trend of saturation in the VIs [42]. The nonlinear equations between NDVI and UF basal area or biomass found in this study also implied this limitation. Our results show that the saturation effect of the NDVI still existed in UFs similar to that in natural vegetations. However, such a kind of limitation could be ignored because UF basal area values from most urban vegetated-areas in this study were much lower than that in natural forest areas and few of the UFs had a canopy density above $60 \%$. In addition, it should be noticed that there are some limitations of our study. The different climatic conditions, specifically precipitation and temperature, may also influence relationships between NDVI and urban vegetation structural attributes. This should be taken into account when applying the method developed in this study to other cities or at different seasons. More research on the relationships between vegetation indices and urban forest structural attributes for different seasons and cities should be conducted in the future.

\subsection{Spatio-Temporal Changes of UF Basal Area under China's Rapid Urbanization and Urban Greening}

In this study, we found that UF increased gradually from 1984, 1995, and 2005 and to 2014 (Table 2 and Figures 7 and 8). The UF changing patterns in the metropolitan area of Changchun, China from 1984 to 2014 responded to combined effects of rapid urbanization and greening policies (Figure 7). UF in China rapidly developed, especially in suburban areas, with the accelerating urban sprawl. This is why we found the gradual increases of UF from 1984 to 2014. The opposite phenomenon was reported in other regions, like most Eastern European cities and the USA [43-46]. This difference might be caused by different urban development patterns in different countries. There are two main patterns of urban development in the world [43]. The first pattern is to sprawl into the wider countryside for urbanized lands and the second is to be densified by urbanization level with development of the existing urbanized area. However, in Europe and the USA, some cities developed by "densifying" through the extension of urban area, which might result in the UF decline. In China, most cities are extending by "sprawl" into the wider countryside. Consequently, more new UFs were established. After having realized the important environmental function of UF in urban ecosystems, local governments in China have set out a series of policies such as "constructing forest cities" (designated by the State Forestry Administration of the People's Republic of China) and invested a large amount of money to introduce green elements into urban central areas in order to resolve such environmental problems [47]. In addition, among these are establishing more new UF parks and community gardens, planting more trees along roads, and especially paying more attention to the establishment of many national UF parks in suburban areas. Therefore, this contributed to the sharp increase of suburban forest UF in the study area from 1984 to 1995 that we can see from our results. Although UF amount increased gradually with the development of urbanization, UF in central urban areas became more and more fragmented due to intense urbanization from 1984 to 1995 . However, along with rapid urban greening in recent years, UF patches became larger and larger, creating a more homogeneous landscape when compared with the spatial patterns in 1995. In spite of the increasing UF amount, some planning strategies are still needed. Conservation or construction plans for the forests in the urban core areas of Changchun are desirable to protect forests from potential loss caused by urbanization, particularly in the first-ring road area in the city where built-up land has increased [22].

\subsection{Implications for Urban Green Infrastructure Management and Planning}

Since 1978 (Chinese reform and opening policies), China has experienced a rapid and unprecedented process of urbanization (Figure 4). For instance, the urban built-up area in Changchun 
increased by $363.5 \%$ from $85 \mathrm{~km}^{2}$ in the $1980 \mathrm{~s}$ to $394 \mathrm{~km}^{2}$ in the 2010 s over a 30 -year period. With the rapid urbanization, many environmental problems in cities have arisen in China, affecting human health, the quality of urban life, and the sustainability of the urban ecosystem [48]. Urban forests considered as an important part of urban ecosystems have many important ecological effects and make a great contribution to the improvement of urban environments $[16,17,49]$. The good spatial and landscape planning can help urban patterns to protect ecosystems and thus support the provision of a needed service and solve urban environmental problems [50]. However, the environmental consequences of planning decisions on the landscape are often undervalued. There might be a lack of adequate information about urban forest at the landscape level. With the development of remote sensing technology, the estimation of spatiotemporal basal area by UF from the remotely sensed imagery is very important for us to enhance understanding the dynamics of UF basal area and has important implications for UF development under China's rapid urbanization and urban greening, providing information about how to establish UF to maximize their ecological functions, particularly for cities where UFs are still under construction. In this study, we found that the spatial distribution of UF basal area was very dynamic, mirroring the intense urbanization and rapid development of urban greening in the city. UF basal area increased gradually from 1984 to 2014 (Figures $\$ 0$ and 12), especially in suburban areas. With the urban expansion, an obvious change of OF basal area first occurred in an urban fringe and suburban area (Figure 12). UF basal area in China underwent a rapid development, especially in suburban areas with the accelerating urban sprawl. Therefore, gradual increases of UF basal area were observed from 1984 to 2014. The UF basal area was also found to be heterogeneous across the different urban gradients (Figure 10). The decreasing trend of $D F$ basal area from suburban areas to downtown areas for all study years is consistent with the decreasing urbanization intensity from downtown areas to suburban areas in China [20]. The changing patterns of UF basal area in the metropolitan area of Changchun, China from 1984 to 2014 responded to combined effects of rapid urbanization and greening policies (Figures 4 and 10).With urban sprawl, UFs developed rapidly, and could serve as important green infrastructure in cities. UF basal area increased from $68 \times 10^{3}$ in 1984 to $224 \times 10^{3}$ in 2014, with an increment of $5.2 \times 10^{3}$ for each year. Meanwhile, our results also showed that most areas in our study area were still covered by the low UF basal area or biomass values. These results may suggest that there is still great potential to increase the capacity of UF basal area and improve urban environments in Changchun. This has some important management implications for urban greening. Firstly, there is still great potential to increase the total area of UFs in Changchun. Currently, the UF cover is only $25 \%$. More trees can be planted and more C can be stored and sequestered. In addition, researchers still need to take some measures for local urban managers to increase UF basal area or biomass. We should seek practical approaches to optimize UF structure to enhance the capacity of these UFs in ecological functions. Some measures could be suggested such as tree species selecting, pruning, and shaping. In practice, native species with fast grow th rates should be planted to improve the capacity of carbon sequestration of UFs. Besides, the multilayer forest communities with a high canopy density and LAI are also the most effective in terms of the ecological effect. In our study, our results also show that the UF patterns are uneven in the study area. Uf cover in suburban areas was higher than that in urban core areas, especially within the first-loop road in Changchun, which could lead to the environmental inequity [51,52]. Therefore, urban planners and policy makers should be concerned with the distribution inequity of UFs and plant more trees to increase the amount of UFs in urban central areas. In recent years, China has selected ecological civilization as the national strategy to build a beautiful China. It will be a great chance for UF development in China. The government should strengthen the building of UF. UF quality also needs to be further improved, especially in terms of the structure and function for secure good dwelling environments. Our work presented here suggests that the use of UF under China's rapid urbanization and urban greening offers significant potential for urban environmental improvement. 

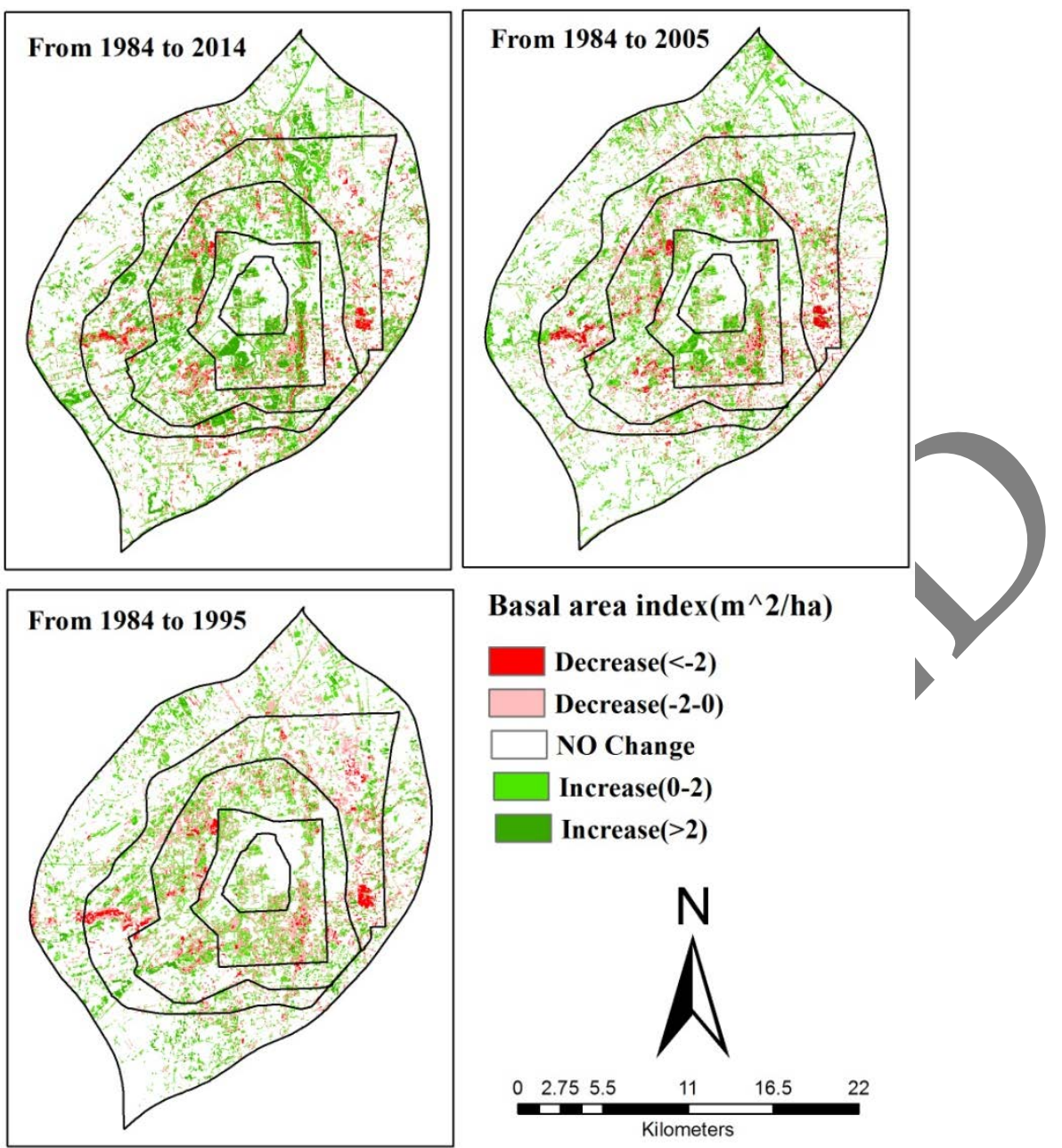

Figure 12. Spatiotemporal changing patterns of UF basal area index in the City of Changchun.

\section{Conclusions}

Based on multi-temporal Landsat TM data $(1984,1995,2005$, and 2014) and UF field survey data, this study explored the potential of using TM imagery to estimate spatio-temporal patterns of UF and its basal area in the City of Changchun, China. The following conclusions could be realized:

(1) Landsat TM imagery could provide a faster and cost-effective method to obtain spatio-temporal patterns of UF and a 30-m resolution UF basal area. NDVI is still a good predictor to estimate and map UF basal area.

(2) In the rapid urbanized region (within the study area) of Changchun City, the UF and its basal area have been found to increase significantly from 1984, 1995, and 2005 to 2014, especially in the outer belts of the city due to urban sprawl. The UF basal area class distribution was skewed toward low values in 1984, 1995, 2005, and 2014, but gradually skewed toward relatively high values from 1984 to 2014.

(3) The results demonstrate that the spatiotemporal pattern of basal area by UF has great implications for urban forest establishment under China's rapid urbanization and urban greening.

The results from our study provide needed baseline information at the landscape scale by producing the relatively high-resolution maps of UF and its basal area. If this study can be used in practice, more time-saving and labor-saving estimations of spatiotemporal UF basal area could be possible to assess the actual and potential role of UFs to improve the urban environment. Furthermore, 
the accurate information of UF and its basal area may allow urban planners to conduct more realistic and better planting designs of UFs at the urban landscape scale.

Author Contributions: Zhibin Ren analyzed the data and wrote the paper; Zhibin Ren and Hongxu Wei finished the field investigation; Xingyuan He and Hongxu Wei helped with designing the research and assisted in data analysis and with editing the manuscript; Haifeng Zheng helped with extracting the spatial information of urban forests.

Funding: This research was supported by Funding for Jilin Environmental Science (2017-16), the National Natural Science Foundation of China (41701210), Science Development Project of Jilin Province, China (20180418138FG), the "Strategic Priority Research Program" of the Chinese Academy of Sciences (KFZD-SW-302-03), and the Foundation for Excellent Young Scholars of Northeast Institute of Geography and Agroecology, CAS (DLSYQ13004).

Acknowledgments: The authors also want to provide our gratitude to the editors and the anonymous reviewers who gave us their insightful comments and suggestions.

Conflicts of Interest: The authors declare no conflict of interest.

\section{References}

1. Cao, S.; Chen, L.; Liu, Z. An investigation of Chinese attitudes towards the environment: Case study using the Grain for Green Project. Ambio 2009, 38, 55-64. [CrossRef] [PubMea]

2. McPherson, E.G.; Simpson, J.R.; Peper, P.J.; Maco, S.E.; Xiao, Q. Municipal forest benefits and costs in five U.S. cities. J. For. 2005, 103, 411-416.

3. Nowak, D.J.; Greenfield, E.J.; Hoehn, R.E. Carbon storage and sequestration by trees in urban and community areas of the United States. Environ. Pollut. 2013, 178, 229-236. [CrossRef] [1 uroMed]

4. Puneet, D.; Chinmaya, S.R.; Yogesh, D. Ecological benefits of urban forestry: The case of Kerwa Forest Area (KFA), Bhopal, India. Appl. Geogr. 2009, 29, 194-200.

5. Young, R.F. Managing municipal green space for ecosystem servíces. Urban For. Urban Green. 2010, 9, 313-321. [CrossRef]

6. Nowak, D.J.; Crane, D.E. Carbon storage and sequestration by urban trees in the USA. Environ. Pollut. 2002, 116, 381-389. [CrossRef]

7. Weng, Q.; Yang, S. Urban air pollution patterns, land use, and thermal landscape: An examination of the linkage using GIS. Environ. Monit. Assess. 2006, 117, 463-489. [CrossRef] [PubMed]

8. Hall, R.J.; Skakun, R.S.; Arsenault, E.J.; Case, B.S. Modeling forest stand structure attributes using Landsat ETM+ data: Application to mapping of aboveground biomass and stand volume. For. Ecol. Manag. 2006, 225, 378-390. [Cros Ref]

9. Lucy, R.H.; Byungman, Y.; Marina, A. Terrestrial carbon stocks across a gradient of urbanization: A study of the Seattle, WA region. Glob. Chang. Biol. 2010, 17, 783-797.

10. Kirnbauer, M.C.; Baetz, B.W.; Kenney, W.A. Estimating the stormwater attenuation benefits derived from planting four monoculture species of deciduous trees on vacant and underutilized urban land parcels. Urban For, Urban Green. 2013, 12, 401-407. [CrossRef]

11. Armson, D.; Stringer, P.; Ennos, A.R. The effect of street trees and amenity grass on urban surface water runoff in Manchester, UK. Urban For. Urban Green. 2004, 12, 282-286. [CrossRef]

12. Bowler, D.E.; Buyung-Ali, L.; Knight, T.M.; Pullin, A.S. Urban greening to cool towns and cities: A systematic review of the empirical evidence. Landsc. Urban Plan. 2010, 97, 147-155. [CrossRef]

13. Shashua-Bar, L.; Hoffman, M.E. Vegetation as climatic component in the design of an urban street-An empirical model for predicting the cooling effect of urban green areas with trees. Energy Build. 2000, 31, 221-235. [CrossRef]

14. Cornelis, J.; Hermy, M. Biodiversity relationships in urban and suburban parks in Flanders. Landsc. Urban Plan. 2004, 69, 385-401. [CrossRef]

15. Godefroid, S.; Koedam, N. How important are large vs. small forest remnants for the conservation of the woodland flora in an urban context? Glob. Ecol. Biogeogr. 2003, 12, 287-298. [CrossRef]

16. Mcpherson, E.G.; Nowak, D.; Heisler, G. Quantifying urban forest structure, function, and value: The Chicago Urban Forest Climate Project. Urban Ecosyst. 1997, 1, 49-61. [CrossRef]

17. Nowak, D.J. Understanding the structure of urban forests. J. For. 1994, 92, 36-41. 
18. Wu, J. The state-of-the-science in urban ecology and sustainability. Landsc. Urban Plan. 2014, 125, $209-221$. [CrossRef]

19. Tian, G.; Liu, J.; Xie, Y.; Yang, Z.; Zhuang, D.; Niu, Z. Analysis of spatio-temporal dynamic pattern and driving forces of urban land in China in 1990s using TM images and GIS. Cities 2005, 22, 400-410. [CrossRef]

20. Zhou, X.; Wang, Y. Spatial-temporal dynamics of urban greenspace in response to rapid urbanization and greening policies. Landsc. Urban Plan. 2011, 100, 268-277. [CrossRef]

21. Yang, J.; Huang, C.; Zhang, Z.; Wang, L. The temporal trend of urban green coverage in major Chinese cities between 1990 and 2010. Urban For. Urban Green. 2013, 13, 19-27. [CrossRef]

22. Zhao, J.; Chen, S.; Jiang, B.; Ren, Y.; Wang, H.; Vause, J.; Yu, H. Temporal trend of green space coverage in China and its relationship with urbanization over the last two decades. Sci Total Environ. 2013, 442, 455-465. [CrossRef] [PubMed]

23. Liu, C.F.; Li, X.M. Carbon storage and sequestration by urban forests in Shenyang, China. Urban For. Urban Green. 2012, 11, 121-128. [CrossRef]

24. Zhang, D.; Zheng, H.; Ren, Z.; Zhai, C.; Shen, G.; Mao, Z.; Wang, P.; He, X. Effects of Forest Type and Urbanization on Carbon Storage of Urban Forests in Changchun, Northeast China. Chin. Geogr. Sci. 2015, 25, 147-158. [CrossRef]

25. Escobedo, F.; Varela, S.; Zhao, M.; Wagner, J.E.; Zipperer, W. Analyzing the efficacy of subtropical urban forests in offsetting carbon emissions from cities. Environ. Sci. Policy 2010, 13, 362-372. [CrossRef]

26. Frolking, S.; Palace, M.; Clark, D.B.; Chambers, J.Q.; Shugart, H.H.; Hurtt, G.C. Forest disturbance and recovery-A general review in the context of space-borne remote sensing of impacts on aboveground biomass and canopy structure. J. Geophys. Res. 2009, 114, 281-296. [Crossh

27. Ingram, J.C.; Terence, P.; Dawson, R.J. Mapping tropical forest structure in southeastern Madagascar using remote sensing and artificial neural networks. Remote Sens. Environ. 2005, 94, 491-507. [CrossRef]

28. Simone, R.F.; Marcia, C.; Carla, B. Relationships between forest structure and vegetation indices in Atlantic Rainforest. For. Ecol. Manag. 2005, 218, 353-362.

29. Ji, L.; Bruce, K.W.; Dana, R.N. Estimating aboveground biomass in interior Alaska with Landsat data and field measurements. Int. J. Appl. Earth Obs. 2012, 18, 451-461. [CrossRef]

30. Lu, D.S.; Paul, M.; Eduardo, B.; Emilio, M. Relationships between forest stand parameters and Landsat TM spectral responses in the Brazilian Amazon Basin. For. Ecol. Manag. 2004, 198, 149-167. [CrossRef]

31. Huang, X.; Huang, X.J.; Chen, C. The Characteristic, Mechanism and Regulation of Urban Spatial Expansion of Changchun. Areal Res. Dev. 2009, 5, 68-72.

32. Chander, G.; Markham, B. Revised Landsat-5 TM radiometric calibration procedures and postcalibration dynamic Ranges. JEEE Trans. Geosci. Remote Sens. 2003, 41, 2674-2677. [CrossRef]

33. Schott, J.R.; Salvaggio, C.; Volchok, W.J. Radiometric scene normalization using pseudoinvariant features. Remote Sens. Environ. 1988, 26, 1-16. [CrossRef]

34. Yang, X.; Lo, C.P. Relative radiometric normalization performance for change detection from multi-date satellite images. Photogramm. Eng. Remote Sens. 2000, 66, 967-980.

35. Nowak, D.J.; Crane, D.E.; Stevens, J.C.; Hoehn, R.E. The Urban Forest Effects (UFORE) Model: Field Data Collection Manual; US Department of Agriculture Forest Service, Northeastern Research Station: Syracuse, NY, USA, 2003.

36. Liu, C.F.; Li, M.M.; He, X.Y.; Chen, W.; Xu, W.Y.; Zhao, G.L.; Ning, Z.H. Concept discussion and analysis of urban forest. Chin. J. Ecol. 2003, 22, 146-149. (In Chinese)

37. Zhou, W.; Troy, A. Development of an object-based framework for classifying and inventorying human-dominated forest ecosystems. Int. J. Remote Sens. 2009, 30, 6343-6360. [CrossRef]

38. Gao, Y.; Mas, J.F. A comparison of the performance of pixel based and object based classifications over images with various spatial resolutions. J. Earth Sci. 2008, 2, 27-35.

39. Baret, F.; Guyot, G. Potentials and limits of vegetation indexes for LAI and APAR assessment. Remote Sens. Environ. 1991, 35, 161-173. [CrossRef]

40. Gower, S.T.; Kucharik, C.J.; Norman, J.M. Direct and indirect estimation of leaf area index, fAPAR, and net primary production of terrestrial ecosystems. Remote Sens. Environ. 1999, 70, 29-51. [CrossRef]

41. Gray, J.; Song, C.H. Mapping leaf area index using spatial, spectral, and temporal information from multiple sensors. Remote Sens. Environ. 2012, 119, 173-183. [CrossRef] 
42. Franklin, J.; Hiernaux, P.H. Estimating foliage and woody biomass in Sahelian and Sudanian woodlands using a remote sensing model. Int. J. Remote Sens. 1991, 12, 1387-1404. [CrossRef]

43. Dallimer, M.; Tang, Z.; Bibby, P.R.; Brindley, P.; Gaston, K.J.; Davies, Z.G. Temporal changes in greenspace in a highly urbanized region. Biol. Lett. 2011, 7, 763-766. [CrossRef] [PubMed]

44. Baycan-Levent, T.; Vreeker, R.; Nijkamp, P.A. The multi-criteria evaluation of greenspaces in European cities. Eur. Urban Reg. Stud. 2009, 16, 193-213. [CrossRef]

45. Kabisch, N.; Haase, D. Green spaces of European cities revisited for 1990-2006. Landsc. Urban Plan. 2013, 110, 113-122. [CrossRef]

46. Nowak, D.J.; Greenfield, E.J. Tree and impervious cover in the United States. Landsc. Urban Plan. 2012, 107, 21-30. [CrossRef]

47. Chinese Urban Forest Website. Available online: http:/ / www.cuf.com.cn/ (accessed on 12 November 2017).

48. Hubacek, K.; Guan, D.; Barrett, J.; Wiedmann, T. Environmental implications of urbanization and lifestyle change in China:Ecological and Water Footprints. J. Clean. Prod. 2009, 17, 1241-1248. [CrossRef]

49. Gómez-Baggethun, E.; Barton, D.N. Classifying and valuing ecosystem services for urban planning. Ecol. Econ. 2013, 86, 235-245. [CrossRef]

50. Deal, B.; Pan, H. Discerning and Addressing Environmental Failures in Policy Scenarios Using Planning Support System (PSS) Technologies. Sustainability 2017, 9, 13. [CrossRef]

51. .Landry, S.M.; Chakraborty, J. Street trees and equity: Evaluation the spatial distribution of an urban amenity. Environ. Plan. 2009, 41, 2651-2670. [CrossRef]

52. Tooke, T.R.; Klinkenberg, B.; Coops, N.C. A geographical approach to identifying vegetation-related environmental equity in Canadian cities. Environ. Plan. 2010, 37, 1040-1056. [CrossRef]

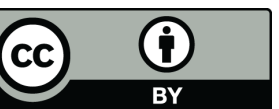

(C) 2018 by the authors. Licensee MDPI, Basel, Switzerland. This article is an open access article distributed under the terms and conditions of the Creative Commons Attribution (CC BY) license (http:/ / creativecommons.org/licenses/by/4.0/).

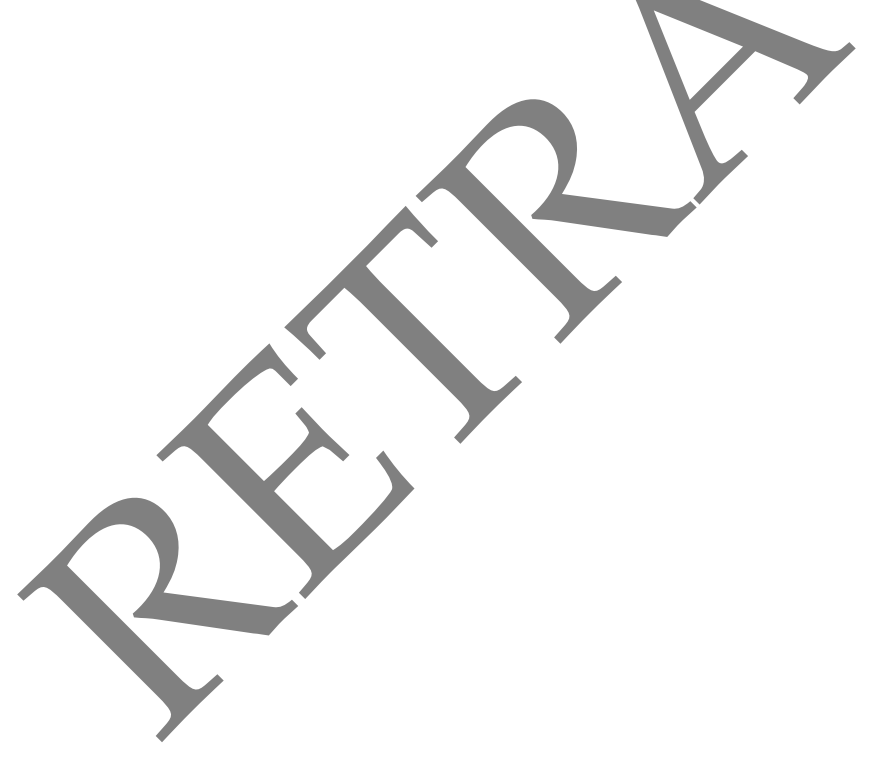

